\title{
Rapid Colorimetric Screening of Elevated Phosphate in Urine: A Charge-Transfer Interaction
}

\author{
Joseph W. Lowdon,* Hikaru Ishikura, Ash Radchenko, Rocio Arreguin-Campos, Renato Rogosic, \\ Benjamin Heidt, Kathia Jimenez Monroy, Marloes Peeters, Hanne Diliën, Kasper Eersels, \\ Thomas J. Cleij, and Bart van Grinsven
}

Cite This: ACS Omega 2020, 5, 21054-21066

Read Online

ACCESS | 네 Metrics \& More | 回 Article Recommendations | st Supporting Information

ABSTRACT: A charge-transfer (CT) interaction between 1,3,5trinitro-2,4-dimethylbenzene (TNX) and anionic phosphate is evaluated, yielding a high band electronic transfer interaction that can be observed as a distinct color change when phosphate is present in solution. The induced interaction was studied using ${ }^{1} \mathrm{H}$ NMR, UV-visible, and Fourier transform infrared spectroscopies. The stoichiometric determination of the interaction was divined by means of continuous variation, applying the Schaeppi-Treadwell method to calculate the binding constant $(k)$. Furthermore, the effect of the polarity of solvents toward the generation of the CT interaction was examined, with multiple solvents considered.

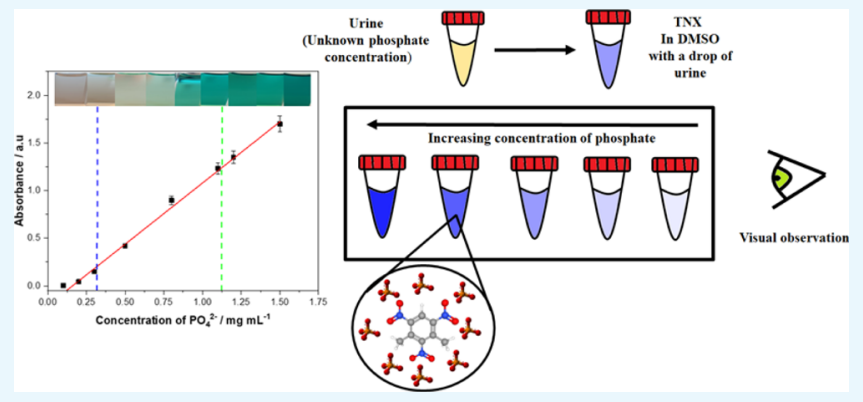
Complex deconstruction studies were undertaken, examining the effects of water on complex destruction and understanding the volumes needed to hinder the CT interaction potency. Specificity and selectivity of the CT interaction were also studied against other biologically relevant species $\left(\mathrm{CH}_{3} \mathrm{CH}_{2} \mathrm{OH}, \mathrm{Na}^{+}, \mathrm{K}^{+}, \mathrm{Ca}^{2+}, \mathrm{Cl}^{-}, \mathrm{HCO}_{3}^{-}, \mathrm{F}^{-}, \mathrm{CH}_{3} \mathrm{COO}^{-}\right.$, and $\left.\mathrm{SO}_{4}{ }^{2-}\right)$, assessing the capabilities of the assay to differentiate anionic species and counter cations that could act as interferences. The role of TNX concentration in CT formation was also analyzed, aiming to optimize the phosphate-sensing assay and improve its limit of detection. The sensing platform was subsequently used to study phosphate concentrations in urine samples to further understand its potential application in biomedical research. To validate the developed technique, urine samples were analyzed for their phosphate content with both the developed sensor and a validated vanadate-molybdate reagent. The results indicate that the sensing method is capable of accurately reporting elevated phosphate levels in urine samples in a rapid and sensitive manner, illustrating that the colorimetric test could be used as a prescreening test for conditions such as hyperphosphatemia or chronic kidney disease.

\section{INTRODUCTION}

Anionic species play a major role in industry, bacterial growth, the environment, and biological processes within the human body. ${ }^{1,2}$ Platforms that are capable of monitoring anionic concentrations in biological fluids are of high value, as they can provide a physician with a fast indication of anionic imbalances that reflect key homeostatic systems in the body. ${ }^{3,4}$ In this manuscript, we introduce a facile chemical sensing platform that is capable of monitoring elevated anionic phosphate concentrations in urine. The developed colorimetric assay has huge potential in the field of biomedical sensing, as phosphate concentrations in bodily fluids are a very accurate representation of the state of a person's health. An imbalance in homeostatic phosphate concentrations is a cause for concern, being indicative of a variety of diseases, and hence there is a need for an easy method of monitoring the concentrations.

Phosphate homeostasis is a complex combination of interactions among bone, intestine, parathyroid gland, and the kidneys, maintaining serum phosphate levels at the optimum value. ${ }^{7}$ Disruptions in one of these processes can lead to conditions such as chronic kidney disease (CKD) or hyperphosphatemia, where phosphate levels within the body become elevated beyond their usual parameters. ${ }^{8}$ The phosphate levels in the body are traditionally monitored by quantification in serum or urine samples by means of ion chromatography or titration. ${ }^{9}$ Chromatographic methods are expensive and time-consuming, with highly specialized columns being required to carry out the analysis, whereas titrations are time-consuming and expensive when automated. The search for alternative sensing techniques that allow for faster detection of small molecules in bodily liquids has intensified over the past few decades as they would allow for a faster diagnosis and, in turn, an improved prognosis for the

Received: June 5, 2020

Accepted: August 5, 2020

Published: August 14, 2020 
patient. ${ }^{10-13}$ Molecular anionic probes could offer such an alternative technique.

Early variations of anionic probes used hydrogen donor functionalities that form binding sites in close proximity to a receptor group, acting as a signaling mechanism. ${ }^{14-20}$ Ferrocene and ruthenium tribispyridyl groups are commonly used as the said receptor groups, demonstrating measurable changes in redox potential or fluorescence because of the change in electronic properties. ${ }^{21-23}$ Redox reactions are also a very common method of colorimetric phosphate analysis, with ammonium molybdate and ammonium vanadate being used in the detection of organophosphates in water samples. ${ }^{24-28}$ Other approaches have also been developed, such as displacement assays, where an indicator (signaling) molecule is prebound to the complex and displaced in the presence of an anion. $^{29}$ The aforementioned methods however require complex sample preparation or multistep synthetic pathways to prepare the probing molecule.

Nitroaromatics on the other hand are easily synthesized organic compounds that contain one or more nitro functionalities $\left(\mathrm{NO}_{2}\right)$ connected to an aromatic ring. ${ }^{30-32}$ These functionalities provide electron-withdrawing effects, leading to the depletion of the electrons in the aromatic system. The electron-deficient environment facilitates an interaction between the depleted aromatic system and anionic species, allowing an intense charge-transfer (CT) interaction to be observed. ${ }^{33-37}$ The resulting electrostatic attraction provides a stabilizing force for the complex generated, yet the nature of this bond is not as stable as a covalent chemical bond. ${ }^{38-40}$ This means that the complex undergoes an electronic transition into an excited electronic state that often occurs in the visible region of the electromagnetic spectrum, providing an intense observable color. ${ }^{41,42} \mathrm{~A}$ common example of a CT complex formation is the reaction between iodine and starch, exhibiting an intense blue CT band. $^{43}$ A similar intense CT interaction is witnessed when reacting nitroaromatic compounds with anionic species. Anions interact with the electron-deficient nitroaromatic compounds, forming a CT complex that has a distinct color (Figure 1). ${ }^{44}$

This research explores the use of 1,3,5-trinitro-2,4dimethylbenzene (TNX) in the field of phosphate sensing, offering an alternative to current methods. The high-intensity blue CT complex formed by TNX in the presence of phosphate enables the novel use of the compound in both

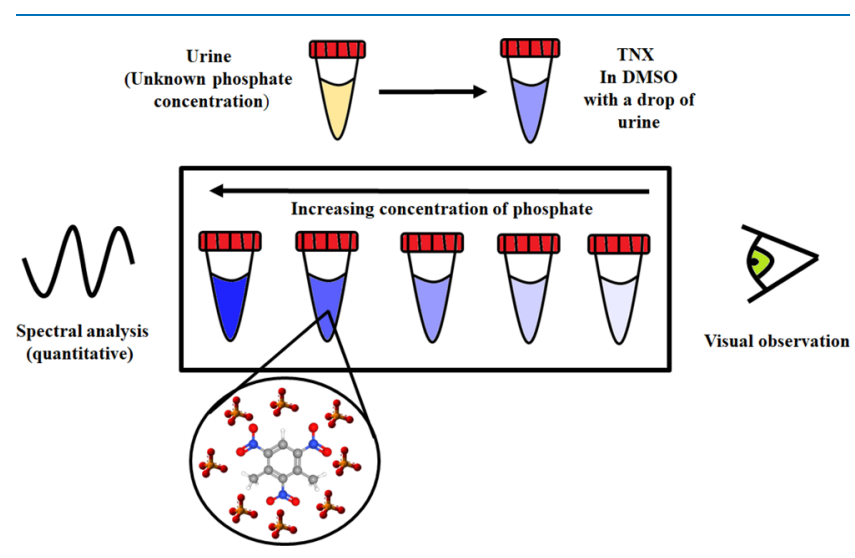

Figure 1. Comprehensive schematic demonstrating the ease of sample analysis with the formation of the $\mathrm{CT}$ interaction. qualitative and quantitative analyses (Figure 1). The nature of the formed CT interaction is fully investigated using Fourier transform infrared (FTIR), ${ }^{1} \mathrm{H}$ NMR, and UV spectroscopies, and the applicability as a phosphate sensing aid is evaluated. The specificity of TNX to form a CT complex with phosphate anions is demonstrated, and the specificity toward other relevant anionic species is also studied. The stability of CT complex formation is established, with TNX concentrations being evaluated in a bid to increase the sensitivity of the sensing platform toward phosphate, finally culminating in the testing of biologically relevant samples for both normal and elevated phosphate concentrations, allowing the confirmation of the plausibility of using TNX as a sensing component in the determination of anionic phosphate concentrations.

\section{RESULTS AND DISCUSSION}

2.1. Spectral Analysis of the Induced CT Interaction. The FTIR absorbance spectra of TNX and the associated phosphate complex recorded in the frequency range 4000-400 $\mathrm{cm}^{-1}$ are shown in Figure 2a, whereas their band assignments are listed in Supporting Information Table S1. In this case, the spectra reflect the free acceptor molecule (TNX), donor species (phosphate), and CT complex $\left(\left[\left(\mathrm{TNX}^{+}\right)\left(\mathrm{PO}_{4}{ }^{3-}\right)\right]\right)$ in dimethyl sulfoxide (DMSO)- $d_{6}$, indicating the characteristic spectra associated with each. The spectra of the CT complex reflect the characteristics of both the donor and the acceptor species, though some peaks have vanished or have been altered because of their interaction. Peak assignments for the complex spectrum were extrapolated from a direct comparison of the spectra for both free donor and free acceptor species. The formation of the CT complex has a direct effect on the peaks observed, with the peak frequencies and intensities changing as a result of the interaction compared to that of free TNX and phosphate.

The use of DMSO- $d_{6}$ as the solvent minimized the residual water present in the chemical system, removing unwanted $\mathrm{OH}$ $\left(3500 \mathrm{~cm}^{-1}\right)$ characteristics from the spectra, and instead introducing a sulfoxide functionality that would not impede notable interactions with the formation of the CT complex. Of the species involved in the interaction, none share sulfoxide characteristics $\left(1058 \mathrm{~cm}^{-1}\right)$, leaving the characteristic wavenumber largely unaffected. The nitroaromatic functionalities found in TNX $\left(1548 \mathrm{~cm}^{-1}\right)$ shift to a higher wavenumber $\left(1657 \mathrm{~cm}^{-1}\right)$ when interacting with potassium phosphate. The donation of electron density to the deficient nitroaromatic system from the phosphate group is seen to establish other characteristics that differ from the two components separately. Mainly, the formation of a broad peak at $3463 \mathrm{~cm}^{-1}$ and the broadening of the peak at $700 \mathrm{~cm}^{-1}$ suggest a bonding interaction between the two species. The generation of the hydroxyl functionality at $3500 \mathrm{~cm}^{-1}$ suggests that the charge on the nitroaromatic compound is localized on the oxygen atoms present in the molecule, stabilized by the interaction of the phosphate group with the electron-deficient aromatic system. The localization of this charge on the oxygen atoms facilitates protonation, therefore giving rise to the formation of hydroxyl functionalities and the characteristics occurring in the spectrum collected.

To fully determine the stoichiometry of the complexation reactions, a Job plot study was undertaken. Phosphate was introduced to TNX, maintaining the overall molar concentrations present in the solution, while also altering the molar ratios of each present. This reaction was conducted in a 

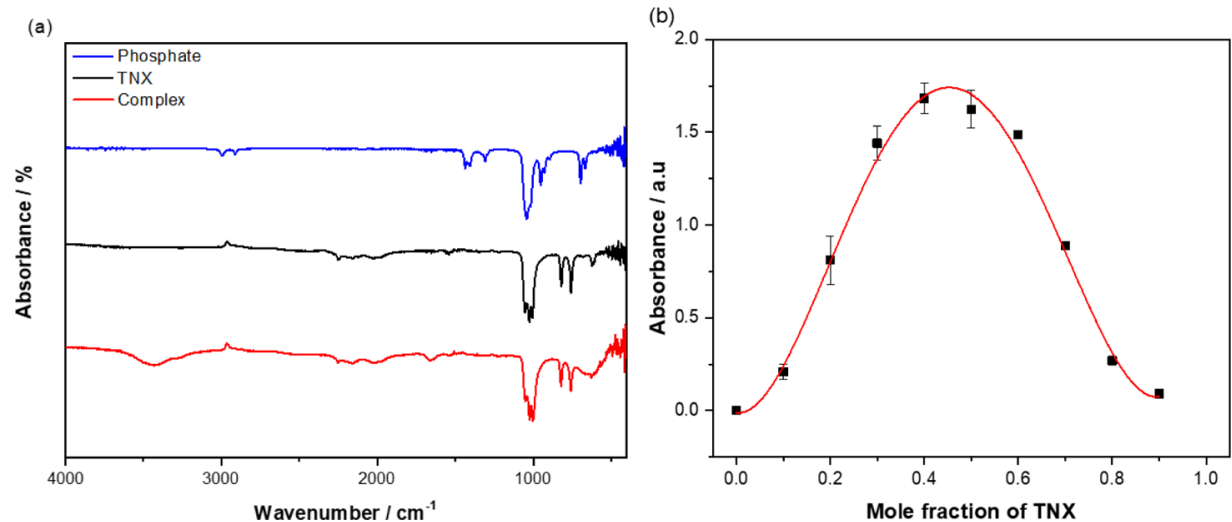

Figure 2. (a) FTIR spectra of TNX (acceptor), potassium phosphate (donor), and CT complex in DMSO- $d_{6}$, and (b) Job's plot reflecting varying molar ratios of TNX and phosphate.
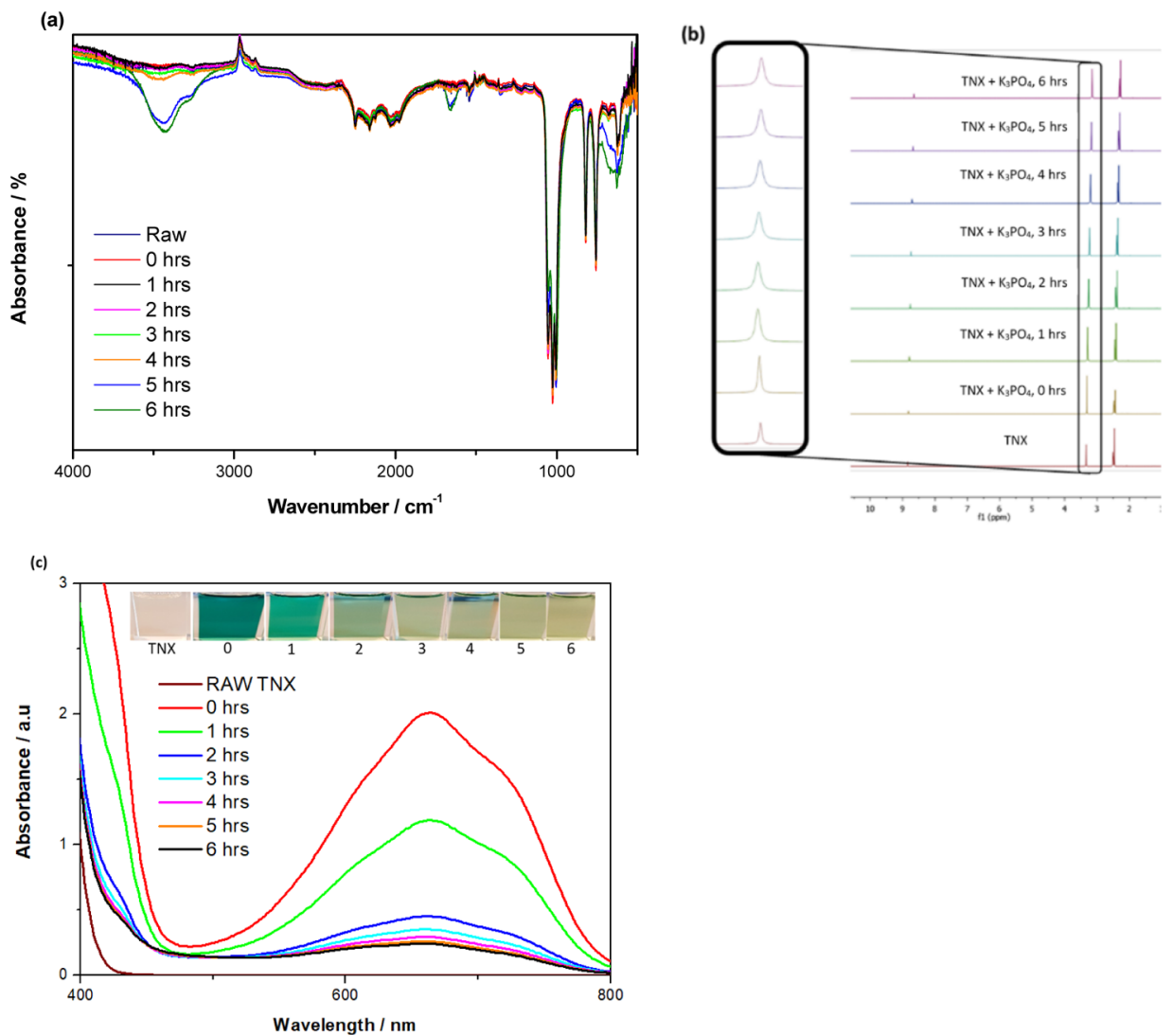

Figure 3. (a) FTIR, (b) ${ }^{1} \mathrm{H}$ NMR, and (c) UV analyses of TNX in DMSO- $d_{6}$, TNX with the initial addition of $\mathrm{K}_{3} \mathrm{PO}_{4}(0 \mathrm{~h})$, and the analysis of the same sample every hour for a total of $6 \mathrm{~h}$.

mixture of $\mathrm{DMSO} / \mathrm{H}_{2} \mathrm{O}(9: 1 \mathrm{v} / \mathrm{v})$ to ensure that phosphate was fully soluble and there was no net change in the amount of water present that could interfere with the interaction. The absorbance $\left(\lambda_{\max }=664 \mathrm{~nm}\right)$ was plotted against the molar fraction of TNX present in the solution, generating the Job plot (Figure 2b). The bell-shaped appurtenance of the plot indicates that $K_{\mathrm{e}}$ is evenly distributed, compared to compounds that present with a sharper plot. The Schaeppi-Treadwell method can be employed to determine the precise value of the binding constant $(K)$, using the experimental maximum change in absorbance $(\Delta E)$ and the theoretical absorbance $\left(\Delta E_{0}\right)$, which is extrapolated from the Job plot (Supporting Information Figure S2). ${ }^{45}$ From these values and the associated calculation, the calculated binding constant for the complex $(K)=2.96 \times 10^{4} \mathrm{M}^{-1}$. This value is similar for the nitroaromatic complex previously reported in the literature, demonstrating a high degree of binding between the receptor compound (TNX) and the ligand (phosphate). ${ }^{17}$ The Job plot demonstrates a maximum at a molar fraction of 0.47 , which indicates a "rounded" stoichiometry of $1: 1 \quad\left(\left[\left(\mathrm{TNX}^{+}\right)\right.\right.$$\left.\left.\left(\mathrm{PO}_{4}{ }^{3-}\right)\right]\right)$. This is a surprising result, considering the charges present in the species involved. The distribution of the charge across the aromatic system and the nitro functionalities present may not be shared equally, giving rise to this observed stoichiometry. We feel that this can be explained by the fact that the electron-withdrawing property of the nitro functionalities present draws electron density from the aromatic center, making the conjugated system electron-deficient, and enables 
the interaction with the negatively charged phosphate species. The CT interaction therefore would stabilize the electronwithdrawing effect of the nitro functionalities, maintaining the observed interaction. Further elucidation of the stoichiometric structure would have to be conducted with more advanced methods (X-ray crystallography) to fully understand the interaction taking place.

A further in-depth study of CT interaction over time was conducted, with TNX being analyzed by FTIR, ${ }^{1} \mathrm{H}$ NMR, and UV spectroscopies before the addition of potassium phosphate, directly after the addition, and thereafter every hour for a $6 \mathrm{~h}$ period (Figure 3). Monitoring the interaction over this extended period elucidated the development of key characteristics within the complex formed. Initially, the FTIR analysis demonstrates no hydroxyl functionality present $(t=0 \mathrm{~h})$, and over the $6 \mathrm{~h}$ period, the characteristic becomes more apparent $\left(3500 \mathrm{~cm}^{-1}\right)$, becoming more intense over time. In tandem to this observation, the band found at $610 \mathrm{~cm}^{-1}$ evolves from a sharp peak, broadening over time. This band is associated with the phosphate species, and the broadening suggests a higher level of interaction between the phosphate group and TNX over time.

The analysis of the ${ }^{1} \mathrm{H}$ NMR spectra elaborates on the interactions displayed by the FTIR data, with hydrogen-bond donor interactions developing over time. The hydrogen-bond donor in DMSO- $d_{6}$ originally presented itself as a sharp small peak $(\delta$ 3.33) in the initial analysis of TNX. After the introduction of phosphate to the system, the peak initially intensified and broadened over the $6 \mathrm{~h}$ period, being indicative of an increase in hydrogen bonding between itself and another species. The aromatic proton found at $\delta 8.85$ is also seen to shift upfield, being indicative of the interaction between the species (an enhanced version of the image can be found in the Supporting Information Figure S3). The integration of the methyl groups $(\delta 2.46,6 \mathrm{H})$ and aromatic proton $(\delta 8.85,1 \mathrm{H})$ remains constant throughout the experiment, allowing the comparison over time to be drawn. This facet of ${ }^{1} \mathrm{H}$ NMR supports the observations noted in the FTIR spectra, confirming that the interaction between TNX and phosphate is in fact a CT interaction that develops over time.

UV spectrometry conducted on the sample over the same time period shows key characteristics of the development of a CT interaction. The spectrum of isolated TNX in DMSO displays a $\lambda_{\max }$ value of $261 \mathrm{~nm}$ that is clearly visible on a more dilute sample, whereas upon the introduction of $\mathrm{K}_{3} \mathrm{PO}_{4}$ to the system, an intense peak at $\lambda_{\max }=664 \mathrm{~nm}$ and a smaller peak at $\lambda=415 \mathrm{~nm}$ are observed (Supporting Information Figure S4). The appearance of the $\lambda_{\max }$ peak is observed visually as a highintensity blue color that is in stark contrast to the colorless solution previously noted. Over the $6 \mathrm{~h}$ measurement window, the intensity of this peak decreases; however, the rate of degradation is not linear (Figure 3c). The intense blue complexation reactions tend to be highly energetic, and over time, the energy in the system decreases, resulting in the degradation of the color. After the $3 \mathrm{~h}$ mark, the rate of degradation is much lower, with the absorbance of the sample becoming more stable. At this point, the FTIR data suggest the formation of $-\mathrm{OH}$ functionalities within the sample, which is a result of the CT interaction being stabilized by protons in the reacting mixture. The color of the complex relaxes to reflect a pale orange, being energetically opposing to the blue interaction originally demonstrated. Plotting the reciprocal of the concentration against time reveals the degradation of the complex to be second order (Supporting Information Figure S5). From the slope of the graph, the degradation constant can be calculated as $k=0.0504 \mathrm{M}^{-1} \mathrm{~S}^{-1}$. The degradation of the complex from its blue form is relatively fast, meaning the absorbance of the analysis is truly time-dependent. This makes the shelf life of the resulting complex less than a few hours, meaning the results of any form of analysis with TNX would be time-sensitive and all measurements in the future must be conducted after the same time period to enable a true comparison.

2.2. Effect of Water on the Interaction of TNX and Phosphate. As the sensing platform is required to perform the evaluation of phosphate in aqueous mediums (urine/ serum), the effect of water on the sensor is of vital importance. The solubility of TNX in water is extremely low, with ice-cold water being used for the precipitation of TNX in the synthetic process. This is inherently problematic when introducing aqueous phosphate to any organic solution containing TNX, as water has a negative impact on the solvated compound. Therefore, after complexation was initiated by means of the addition of potassium phosphate $\left(5 \mathrm{mg} \mathrm{mL}^{-1}\right)$, the systematic addition of deionized (DI) water began while monitoring the absorbance $\left(\lambda_{\max }=664 \mathrm{~nm}\right)$ of the solution (Figure 4).

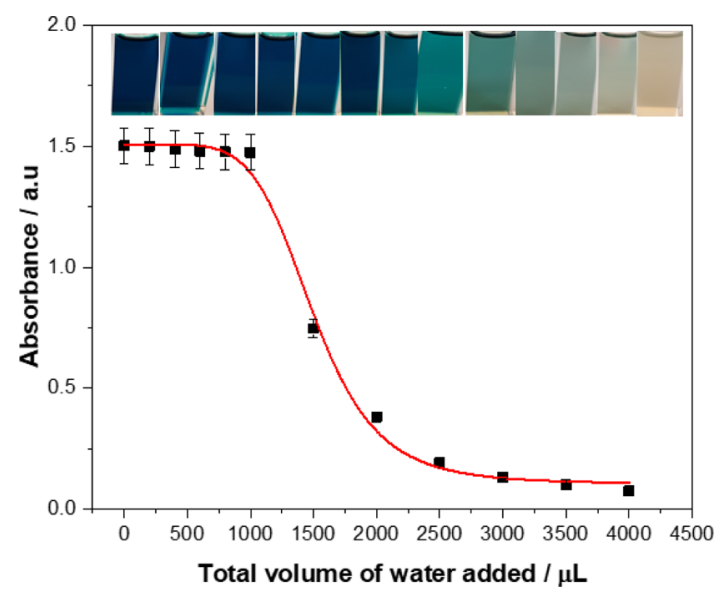

Figure 4. Absorbance $\left(\lambda_{\max }=664 \mathrm{~nm}\right.$ ) of the CT interaction (TNX in DMSO, $5 \mathrm{mg} \mathrm{mL}^{-1}, 6 \mathrm{~mL}$ ) as the total volume of water in the system increases after the initiation $(1 \mathrm{~min})$ of complexation with $50 \mu \mathrm{L}$ of $\mathrm{K}_{3} \mathrm{PO}_{4}\left(5 \mathrm{mg} \mathrm{mL}{ }^{-1}\right)$.

Visually, it becomes inherently clear that adding low amounts of water to the TNX solution in DMSO (less than 1-6 $\mathrm{mL}$ of solution) does not affect the formation of the complex. Adding more water will rapidly result in a decrease in absorption as TNX precipitates, and the absorption will rapidly fall to a value only marginally above baseline when the volume of water added reaches $3 \mathrm{~mL}$. After this, the signal stays more or less stable, and the minor absorption observed in the data can be attributed to the cloudy precipitate. In order to illustrate the importance of staying below the threshold of water volume in the sample under analysis, the data were fit using OriginPro 8 (OriginLabs Corporation, Northampton, MA, United States) using a sigmoidal logistic fit $\left(f(x)=A_{2}+\frac{\left(A_{1}-A_{2}\right)}{1+\left(x / x_{0}\right)^{p}}\right)$. The data nicely illustrate the S-shaped curve which illustrates the effect of water volume on the solubility of TNX and, therefore, the usability of the sensor in aqueous samples (red line, $R^{2}=$ 0.99582 ). These results indicate that when the system is to be 

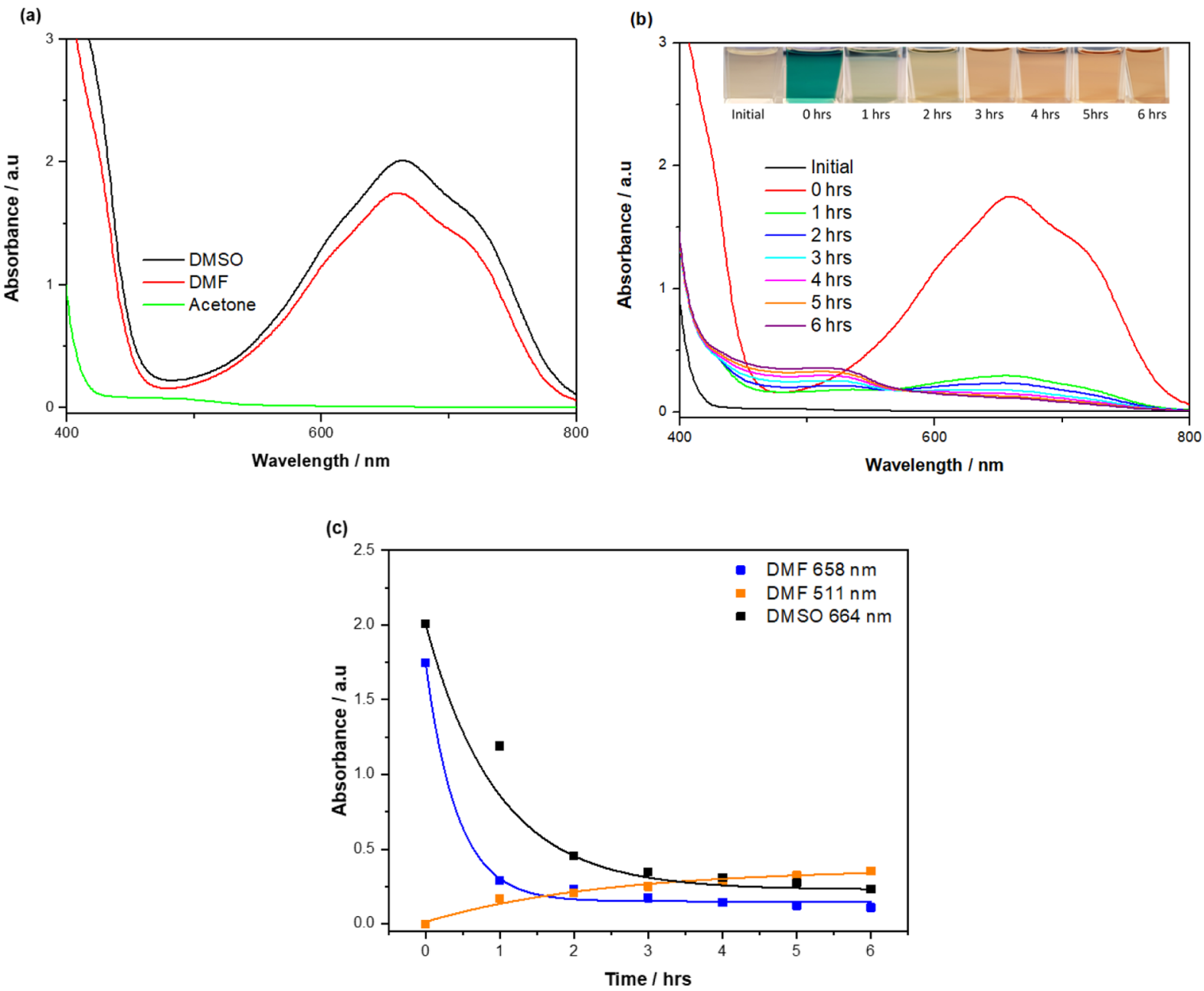

Figure 5. (a) UV spectrometry analysis of DMSO, acetone, and DMF as solvents in the CT interaction between TNX and phosphate, with a further in-depth (b) time-dependent study over the course of $6 \mathrm{~h}$, measuring the stability of the complexation in DMF. (c) Comparison of absorbance intensities in the complex for $\operatorname{DMF}(\lambda=511,658 \mathrm{~nm})$ and DMSO $\left(\lambda_{\max }=664 \mathrm{~nm}\right)$.

used for detecting phosphate in aqueous samples, the total water content of the reaction mixture should not exceed $14 \%$ of the initial volume.

2.3. Solvent Dependency on the CT Interaction Induction. To further understand the interaction occurring between TNX and phosphate in solution, various solvents were considered. Initially, DMSO was the solvent of choice as TNX demonstrated good solubility and DMSO is highly miscible with water making it ideal for the analysis on aqueous samples. Other solvents that shared these properties are dimethylformamide (DMF) and acetone, with both solvating TNX with ease and being miscible with water. Upon the addition of aqueous $\mathrm{K}_{3} \mathrm{PO}_{4}\left(5 \mathrm{mg} \mathrm{mL}^{-1}\right)$, the UV spectra of the resulting reaction were recorded and compared for each of the solvents (Figure 5a). The spectrum for TNX in acetone largely remained unchanged, with no absorption peak visible above $400 \mathrm{~nm}$ and visually no color change observed, concluding that acetone was unsuitable for further testing. As DMSO, DMF, and acetone are similar in nature, the CT interaction may be added by the polarity of the solvent involved. This is supported by the fact that acetone (relative polarity $=0.335$ ) produced no CT absorbance peak, and DMF (relative polarity $=0.386$ ) stimulates a weaker absorbance compared to that of DMSO (relative polarity $=0.444$ ). The analysis of the interaction between TNX and phosphate in DMF provided an intense absorption peak $(\lambda=658 \mathrm{~nm})$, with the observed color of the solution turning dark green. This observation is in line with that of DMSO; however, the absorption band occurs at a lower wavelength. The absorption of the lower wavelength suggests the characteristics about the stability of the complex formed but does not suggest the occurrence of less CT interactions, as the initial absorbance is comparable with that of the interaction in DMSO. The interaction in DMF was consequently studied more in depth, analyzing the sample every hour for $6 \mathrm{~h}$ (Figure $5 b)$.

The initial introduction (Figure $5 \mathrm{~b}, 0 \mathrm{~h}$ ) of phosphate to the DMF-based solution generates a large absorbance peak at $\lambda_{\max }$ $=658 \mathrm{~nm}$ that is visually observed as an intense blue color. This color intensity rapidly depletes, with the observable color becoming less distinctive within the first hour and the measured absorbance being 8 times weaker. Over the remaining period $(2-6 \mathrm{~h})$, the color continues to change from the original blue to a more prominent orange. The absorption data were plotted with time and compared to a similar experiment in DMSO. These data, presented in Figure $5 c$, show a sharp exponential decrease in absorption for DMF in the first hour that gradually levels off to a value only marginally above baseline. The data follow an exponential decay that was fit in Origin using the equation: $f(x)=A_{1} \times$ $\mathrm{e}^{-x / t_{1}}+y_{0}$. In DMSO, a similar pattern can be observed, but the 

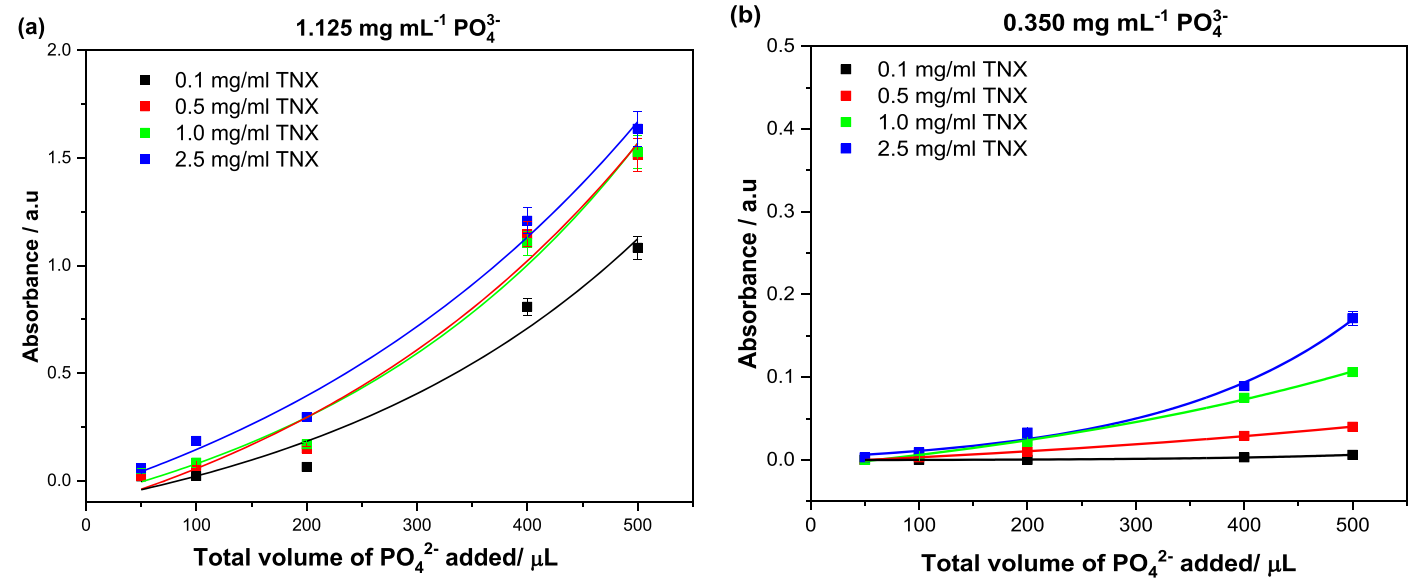

Figure 6. Absorbance $\left(\lambda_{\max }=664 \mathrm{~nm}\right)$ against volume graphs for the varying addition $(50-1000 \mu \mathrm{L})$ of physiologically relevant concentrations of phosphate (a) 1.125 and (b) $0.350 \mathrm{mg} \mathrm{mL}^{-1}$ to $6 \mathrm{~mL}$ of TNX in DMSO at varying concentrations $\left(0.1-2.5 \mathrm{mg} \mathrm{mL}^{-1}\right)$.
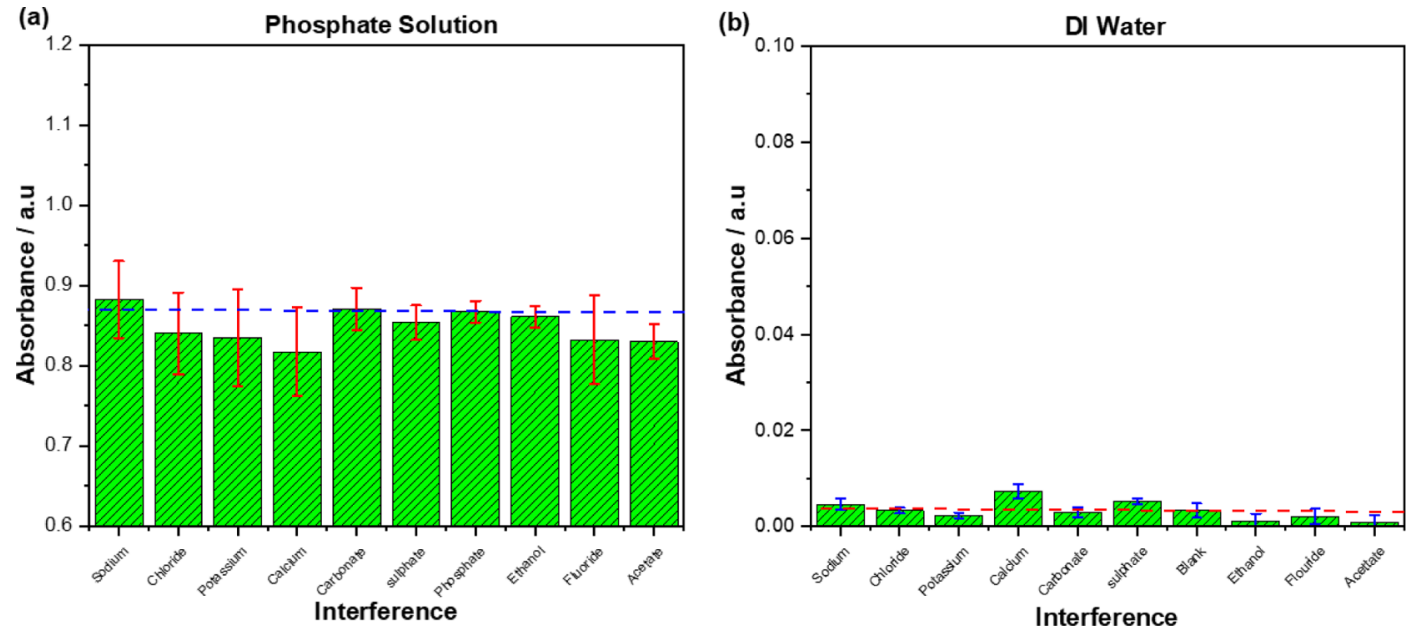

Figure 7. Absorbance $\left(\lambda_{\max }=664 \mathrm{~nm}\right)$ of the CT interactions with (a) phosphate solution spiked with various species, and each species in (b) DI water in the absence of phosphate. Error bars were generated as $1 \mathrm{SD}$ from the mean reading for each species.

time constant for the exponential decay is much higher than that we observed in DMF (0.4257 and 1.3065 s, respectively), indicating that the complex is more stable in polar solvents. The peak observed at $\lambda=511 \mathrm{~nm}$ in DMF could be a consequence of the complex degradation into a more stable form. The color of the solution does become more yellow/ orange slowly over time, and this would give rise to a lower absorbance peak being observed. The exponential growth of the signal, however, is much slower, as indicated by the much higher time constant of $2.4004 \mathrm{~s}$. These fits mainly indicate that the complex degrades rapidly over time and that the absorption measurement for measuring the anion concentration in unknown samples should be performed as soon as possible upon introducing the sample to the TNX solution.

2.4. Optimization of TNX Concentration and Volume of Sample Introduced for the Formation of the CT Complex. The concentration dependency of TNX in DMSO was investigated alongside the volume of aqueous phosphate added to the sensor to determine the optimum value of these two factors. To ensure the calibration was biologically relevant, the physiological minimum and maximum phosphate excretion values were tested. An average human excretes $800-2000 \mathrm{~mL}$ of urine a day, with the amount of phosphate ranging 700-900 mg. ${ }^{46}$ Thus, two concentrations from each extreme of these factors were calculated to be 0.350 and $1.125 \mathrm{mg} \mathrm{mL}^{-1}$, allowing the sensing platform to be attuned appropriately (Figure 6).

Both the upper and lower concentration limits were introduced to the different concentrations of TNX, and the $\lambda_{\max }$ absorbance for each addition was plotted against the volume $(\mu \mathrm{L})$ of phosphate added. The data were fit using OriginPro 8 (OriginLabs Corporation, Northampton, MA, United States) with an exponential $\left(y=a \mathrm{e}^{b}\right)$ growth fit for both phosphate concentrations. The corresponding $R^{2}$ values for the data that were fit for both concentrations can be found in the Supporting Information Table S6. The data were analyzed with respect to the absorbances that fit within the range of $0.05-1.5$ au to ensure that the absorbances generated by the sensor remain in a reliable range for both the upper and lower limits of phosphate concentrations. The addition of phosphate between 50 and $200 \mu \mathrm{L}$ of $1.125 \mathrm{mg} \mathrm{mL}^{-1}$ to the different TNX concentrations all generated a CT interaction response of less than 0.5 au and less than 0.05 au for the lower limit of $0.350 \mathrm{mg} \mathrm{mL}^{-1}$. This is less than ideal for the measurements of phosphate in real-world samples as no induced measurable response would be possible for lower phosphate concentrations, and higher phosphate concentrations would not provide a notable response. The addition of 
$500 \mu \mathrm{L}$ of $1.125 \mathrm{mg} \mathrm{mL}^{-1}$ phosphate generates a response greater than 1.5 a.u, meaning higher concentrations would generate an absorbance greater than this and therefore would risk values outside the reliable range. Therefore, addition of $400 \mu \mathrm{L}$ provides an absorbance within the range specified and is the optimum volume out of those tested. The same principal range was then applied to the concentration of TNX used to calibrate the volume of phosphate added. At the upper limit, there is a clear difference between $0.1 \mathrm{mg} \mathrm{mL}^{-1}$ and the other values; however, there is little change in absorbance for the other concentrations. This change is more evident in the analysis of the lower limit, where each concentration gives a clearly different absorbance. Both 0.1 and $0.5 \mathrm{mg} \mathrm{mL}^{-1}$ give an absorbance response below the desired value, whereas $2.5 \mathrm{mg}$ $\mathrm{mL}^{-1}$ gives a more intense absorbance beyond the desired threshold. This reasoning gives rise to selecting a $1 \mathrm{mg} \mathrm{mL}^{-1}$ concentration of TNX in DMSO for the optimized sensing of phosphate in aqueous solutions, with a $400 \mu \mathrm{L}$ sample introduction volume.

2.5. Potential Anionic and Cationic Interferences. Multiple anionic/cationic species were chosen to evaluate the capability of TNX to form a CT complex, with the species selected being most commonly found in urine. The species tested included $\mathrm{CH}_{3} \mathrm{CH}_{2} \mathrm{OH}, \mathrm{F}^{-}, \mathrm{CH}_{3} \mathrm{COO}^{-}, \mathrm{Na}^{+}, \mathrm{K}^{+}, \mathrm{Ca}^{2+}$, $\mathrm{Cl}^{-}, \mathrm{HCO}_{3}{ }^{-}$, and $\mathrm{SO}_{4}{ }^{2-}$, providing a range of interferences for TNX to potentially interact with. The parameters used for the introduction of the species were as previously optimized, with $6 \mathrm{~mL}$ of TNX solution ( $1 \mathrm{mg} \mathrm{mL}^{-1}$ in DMSO) and $400 \mu \mathrm{L}$ of "spiked" aqueous $\mathrm{PO}_{4}{ }^{3-}$ being added. The phosphate samples were spiked individually with physiologically relevant concentrations of each species, allowing the response to each of the interferences to be monitored (Figure $7 \mathrm{a}$ ). The phosphate concentration throughout the experiment was $0.85 \mathrm{mg} \mathrm{mL}^{-1}$, representing a midrange concentration between the upper and lower physiological limits. In parallel to this, each interference was isolated and analyzed in the absence of phosphate to study the interactions of the species with TNX further (Figure $7 \mathrm{~b}$ ).

Each of the data points was replicated in triplet, allowing the mean and standard deviation (SD) of each sample to be calculated. The data were fit using OriginPro 8 (OriginLabs Corporation, Northampton, MA, United States), generating a bar chart comparing each sample. All the interferences in the phosphate solution produced a reading within $1 \mathrm{SD}$ of the mean response of the pure phosphate solution (blue dashed line). Of the interferences present, chloride, potassium, sulfate, and calcium suppressed the absorbance normally observed by the formation of the CT interaction, whereas sodium and carbonate enhance the signal marginally. The level of suppression was different for each of the species, with calcium providing the largest of the effects recorded. Calcium being present as a +2 cation in comparison to the other cations of +1 charge may be the reason for this effect. The greater charge on calcium provided a stronger potential interaction with TNX and phosphate present in the solution, therefore suppressing the signal. Another plausible explanation is that calcium interacts with phosphate present in the solution forming calcium phosphate, which has poor solubility. Therefore, it can be stipulated that calcium does not directly interfere with the complexes formed but reduces the amount of phosphate dissolved in the solution, producing a different yet similar result. This speculation can be backed experimentally by the formation of a light precipitate observed after the calcium solution was introduced to the sensing solution. Fluoride and acetate anions caused a reduction in absorbance similar to that of calcium, which is surprising, as previous literature has demonstrated how these species illicit an absorbance peak in the presence of nitroaromatics. ${ }^{17}$ The molecules in question are however more complex than TNX, indicating the mechanism behind the slight quenching effect observed is probably different from the enhancement mechanism previously investigated. A further surprising result is the lack of interaction sulfate has with TNX, with this showing a marginal decrease in absorbance in the presence of phosphate and no interaction in its absence. Considering the similarities of the species, it must be assumed that the slightly more basic nature of phosphate is the causality of this observation. As for the interferences ran in DI water, none of the interferences stimulated a CT interaction great enough to be observed by the naked eye, and the absorbances measured were similar to that of the blank (red dashed line). The error bars of all of the species, bar calcium, fell within 1 SD of the blank; however, the absorbance that was reported is only marginally greater than that of the blank that was ran. It can therefore be deduced from the biologically relevant species tested that none have any meaningful impact on the formation or suppression of the CT interaction induced in the presence of phosphate.

2.6. Optimized Dose-Response for Phosphate. With the optimized values of TNX concentration and the volume of sample that should be added considered, a dose-response curve was constructed for the physiological phosphate range. Additions of $400 \mu \mathrm{L}$ of phosphate $\left(0.10-1.5 \mathrm{mg} \mathrm{mL}^{-1}\right)$ to TNX in DMSO $\left(6 \mathrm{~mL}, 1 \mathrm{mg} \mathrm{mL}^{-1}\right)$ were studied, quantifying the formation of the CT complex by UV spectroscopy alongside visual verification. It is important that the response generated by the CT interaction reflects the physiological range in a linear fashion, with the suppressed and elevated phosphate levels also considered.

To generate a calibration graph relating the concentration of phosphate and the absorbance observed from the CT interaction, the absorbance of the most intense peak $\left(\lambda_{\max }=\right.$ $664 \mathrm{~nm})$ was plotted against $\left[\mathrm{PO}_{4(\mathrm{aq})}{ }^{2-}\right]$ (Figure 8). The data were fit using OriginPro 8 (OriginLabs Corporation, Northampton, MA, United States) using a linear fit $(y=m x+c)$

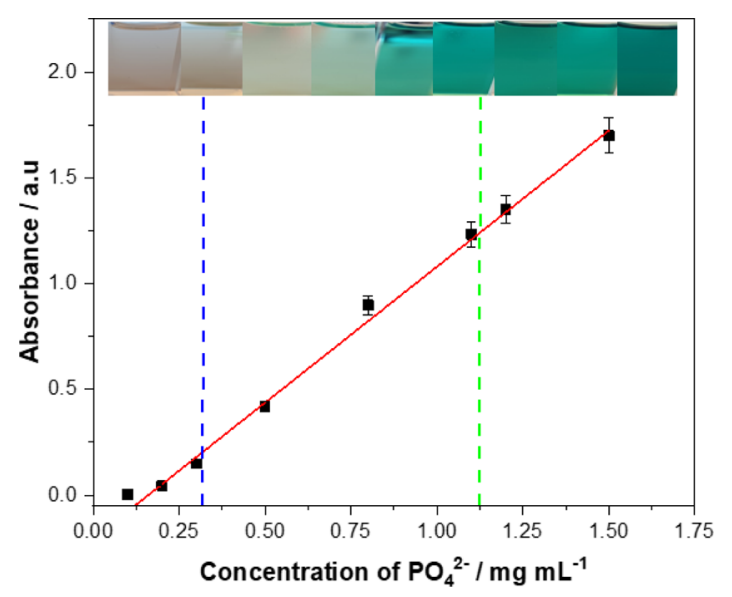

Figure 8. Average dose-response $\left(\lambda_{\max }=664 \mathrm{~nm}\right)$ for the CT interaction upon the addition of phosphate in the range of $0.10-1.50$ $\mathrm{mg} \mathrm{mL} \mathrm{m}^{-1}$, error bars $\pm 1 \mathrm{SD}$. The blue dashed line represents the lower physiological concentration $\left(0.35 \mathrm{mg} \mathrm{mL}^{-1}\right)$ and the green dashed line represents the upper physiological concentration (1.125 $\mathrm{mg} \mathrm{mL} \mathrm{L}^{-1}$ ) of phosphate in urine. 
Table 1. Definitions Relating to the LoB, LoD, and LoQ as Specified by Armbruster et al. ${ }^{47}$

\begin{tabular}{|c|c|c|c|}
\hline parameter & sample type & sample characteristics & equation \\
\hline LoB & $\begin{array}{l}\text { sample containing no analyte, e.g., zero level } \\
\text { calibrator }\end{array}$ & $\begin{array}{l}\text { negative or very low concentration sample that is commutable with patient } \\
\text { specimens }\end{array}$ & $\begin{array}{l}\mathrm{LoB}=\text { mean }_{\text {blank }}+1645 \\
\quad\left(\mathrm{SD}_{\text {blank }}\right)\end{array}$ \\
\hline LoD & $\begin{array}{l}\text { sample containing a low concentration of } \\
\text { analyte, e.g., dilution of the lowest } \\
\text { concentration calibrator }\end{array}$ & $\begin{array}{l}\text { low concentration samples, such as a dilution of the lowest non-negative } \\
\text { assay kit calibrator or patient specimen matrix containing a weighed out } \\
\text { amount of analyte, commutable with patient specimens }\end{array}$ & $\begin{array}{l}\mathrm{LoD}=\mathrm{LoB}+1.645 \\
\quad\left(\mathrm{SD}_{\text {low concentration sample }}\right)\end{array}$ \\
\hline LoQ & $\begin{array}{l}\text { sample containing a low concentration of } \\
\text { analyte at the expected LoQ, e.g., sample } \\
\text { with the concentration at or above LoD }\end{array}$ & $\begin{array}{l}\text { low concentration samples at or above the concentration of the LoD; } \\
\text { analyte concentration must be sufficient to produce analytical signals that } \\
\text { meet predetermined targets for bias, imprecision, and total error }\end{array}$ & LoQ $\geq$ LoD \\
\hline
\end{tabular}

Table 2. Analysis of Phosphate Concentrations in $24 \mathrm{~h}$ Urine Using the TNX-Based Phosphate Sensor and the Ammonium Vanadate-Molybdate Reagent

\begin{tabular}{|c|c|c|c|c|}
\hline \multirow[b]{2}{*}{ analysis } & \multicolumn{2}{|c|}{ TNX analysis $\left(\lambda_{\max }=664 \mathrm{~nm}\right)$} & \multicolumn{2}{|c|}{ vanadate - molybdate reagent $\left(\lambda_{\max }=308 \mathrm{~nm}\right)$} \\
\hline & absorbance & concentration $\left(\mathrm{mg} \mathrm{mL}^{-1}\right)$ & absorbance & concentration $\left(\mathrm{mg} \mathrm{mL}^{-1}\right)$ \\
\hline 1 & 0.549 & 0.585 & 1.150 & 0.758 \\
\hline 2 & 0.505 & 0.554 & 1.140 & 0.743 \\
\hline 3 & 0.497 & 0.549 & 1.136 & 0.740 \\
\hline mean value & $0.517 \pm 0.028$ & $0.562 \pm 0.020$ & $1.142 \pm 0.007$ & $0.747 \pm 0.010$ \\
\hline
\end{tabular}

dose-response curve $\left(R^{2}=0.9962\right)$. The linear range of the sensor is more than sufficient to analyze the phosphate levels in urine within the physiological range. The range even extends beyond the physiological values, with the concentrations both above and below showing linearity, facilitating the possible confirmation of both hypo- and hyperphosphatemia with the sensor.

As this method is aimed toward clinicians and the point-ofcare (PoC) sector for the analysis of urine samples, analytical sensitivity has to be considered. Therefore, the limit of blank (LoB), limit of detection (LoD), and limit of quantitation (LoQ) need to be specified (see Table 1 for definitions). The Clinical and Laboratory Standards Institute (CLSI) provides these guidelines (EP17), for the determination of LoD and LoQ. ${ }^{47}$

Conforming to these definitions standardizes the parameters being assessed, adding reliability to the sensing method. Following the guidelines set, the value for each parameter are as follows: $0.001 \mathrm{mg} \mathrm{mL}^{-1}$ (LoB), $0.164 \mathrm{mg} \mathrm{mL}^{-1}$ (LoD), and $\geq 0.164 \mathrm{mg} \mathrm{mL}^{-1}$ (LoQ). The proposed calculated LoD is therefore much lower than the lowest physiological concentration of phosphate, meaning the sensor can reliably produce a result at this value. If the sensor was to be commercialized, the sample size for these tests must be increased to increase robustness and the statistical confidence in the results. However, for a proof-of-principle study, these values are reliable and give an accurate representation of the data collected.

2.7. Validation Study of Phosphate in Urine. To validate the TNX-based phosphate sensing method, $24 \mathrm{~h}$ urine samples were subject to the technique, alongside a validation method to confirm the results of the analysis. The chosen colorimetric validation method uses a well-documented vanadate-molybdate reagent, ${ }^{24-27}$ producing a clear yellow color in the presence of phosphate. A calibration was initially created by introducing varying phosphate concentrations $\left(0.1-1.5 \mathrm{mg} \mathrm{mL}^{-1}\right)$ to known amounts of the reagent, while monitoring the absorbance spectrum with a UV spectrometer $\left(\lambda_{\max }=308 \mathrm{~nm}\right)$ (Supporting Information Figure S7a). The absorbance was plotted against the concentration of phosphate introduced (Supporting Information Figure S7b), yielding a dose response with $R^{2}=0.99597$. The raw absorbance spectra
(Supporting Information Table S8) from the analysis of the urine with both methods were then compared to their corresponding calibration, converting the data into meaningful concentrations. The urine sample analyzed was collected from a healthy male (age 26) over the course of an average day, with the analysis conducted with both the TNX-based technique and the established vanadomolybdophosphoric acid method for confirmation (Table 2). The analysis was repeated in triplet, with the average concentration and SD reported for both techniques.

The analysis of the urine with both methods proved to give phosphate concentrations in the physiological range. The analysis with the developed TNX-based sensor provided a mean concentration of $0.562 \pm 0.020 \mathrm{mg} \mathrm{mL}^{-1}$, which was lower than $0.747 \pm 0.010 \mathrm{mg} \mathrm{mL}{ }^{-1}$ that the vanadatemolybdate reagent produced. The minor discrepancy in the value $\left(0.185 \mathrm{mg} \mathrm{mL}^{-1}\right)$ demonstrates that the values are in a similar range. The lower value from the TNX-based analysis could be caused by organic interferences that do not affect the vanadate-molybdate reagent. This said, the comparison of the values illustrates that this low-cost TNX-based analysis can provide somewhat acceptable readings of phosphate in a biological sample. This capability combined with the ease of use and low-cost nature of the TNX-based sensor is reason enough to consider the method for rapid semiquantitative PoC testing, with more advanced methods used for complete confirmation. Therefore, the comparison of the two methods indicates that the TNX-based sensor stands up to the vanadate-molybdate reagent. Moreover, as vanadomolybdophosphoric acid presents itself as a yellow color in the presence of phosphate, the urine samples had to be pretreated with activated carbon to remove any colored elements prior to analysis. However, the color of the urine was not an issue for the TNX-based sensor, as the CT interaction caused by the presence of phosphate shows an unnatural blue tone. The preparation of the vanadate-molybdate reagent is more complex and costlier than that of the dissolution of TNX in $\mathrm{DMSO}$, and also the $\mathrm{CT}$ interaction does not require concentrated hydrochloric acid to occur. Furthermore, the resulting acid produced by the vanadate-molybdate reagent in the presence of phosphate is much greater in toxicity than that of TNX or its CT complex. Overall, the TNX-based phosphate 
sensor produced comparable results, without involving expensive chemical reagents or the pretreatment of samples.

\section{CONCLUSIONS}

${ }^{1} \mathrm{H}$ NMR, FTIR, and UV analyses of TNX interacting with phosphate in DMSO- $d_{6}$ proved that TNX forms a CT complex with the anionic species, generating an intense absorption peak at $\lambda_{\max }=664 \mathrm{~nm}$. The intensity of this peak was seen to degrade over the period of $6 \mathrm{~h}$, diminishing the initial intense blue to a less energetic orange tone. The use of ${ }^{1} \mathrm{H}$ NMR determined the interactions occurring between TNX and phosphate to be noncovalent, with hydrogen-bond donation increasing over a $6 \mathrm{~h}$ period. The FTIR analysis elucidated the electronic nature of these interactions, indicating the formation of $\mathrm{OH}$ functionalities over time and the shifting over various functionality wavenumbers. The interaction was further understood by conducting a Job plot study, revealing the stoichiometric ratio of the interaction to be $1: 1$ (TNX/ phosphate). The binding constant was then derived $(K=2.96$ $\left.\times 10^{4} \mathrm{M}^{-1}\right)$, revealing the speed at which complexation occurs.

As TNX has poor solubility in water, the effect of water on the formation of the $\mathrm{CT}$ interaction was studied. The CT interaction was initiated in DMSO- $d_{6}$ with the addition of phosphate, and slowly the volume of water in the system was increased, with the absorbance $\left(\lambda_{\max }=664 \mathrm{~nm}\right)$ monitored. A total volume of $1 \mathrm{~mL}$ of water could be introduced before the absorbance was seen to dramatically decrease, with the complexation sharing characteristics with a sigmoidal degradation pattern. An overall volume of $4 \mathrm{~mL}$ of water could be achieved before the solution became cloudy to analyze with UV spectroscopy. Therefore, based on these observations, a volume of water no greater than $1000 \mu \mathrm{L}$ (16\% of the initial volume) would be added in future experiments, thus ensuring that the absorbance of the complex would not be impeded by the presence of water in solution.

A variety of solvents were investigated in a bid to optimize the observed CT interaction, with acetone, DMSO, and DMF evaluated. These solvents were chosen based upon their miscibility with water, as this is a necessary facet if aqueous samples were to be introduced to the TNX mixture. Of the solvents tested, acetone did not facilitate the CT interaction observed when phosphate was introduced into the system. DMF and DMSO facilitate the interaction; however, the stability of the complex in DMF was much less than that in DMSO. Herein, DMSO was the solvent of choice for further experimentation.

To optimize the sensor capabilities, the relationship between the concentration of TNX and the volume of analyte added was studied in detail. To achieve this, the upper and lower physiological concentrations $\left(0.350\right.$ and $\left.1.125 \mathrm{mg} \mathrm{mL}^{-1}\right)$ of phosphate were selected, calibrating the sensing platform toward the detection of these extremes. The concentration of TNX proved less important in the detection of higher concentrations, with 1 and $0.5 \mathrm{mg} \mathrm{mL}^{-1}$ responding to the presence of phosphate in a similar manner; however, at lower concentrations, the $1 \mathrm{mg} \mathrm{mL}{ }^{-1} \mathrm{TNX}$ solution allowed greater sensitivity toward phosphate. Based on this, the optimum sample volume introduced to the system was found to be 400 $\mu \mathrm{L}$, giving absorbance readings within the reliable range of the UV spectrometer for both extremes of the physiological range.

Multiple biologically relevant interference species $\left(\mathrm{Na}^{+}, \mathrm{K}^{+}\right.$, $\mathrm{Ca}^{2+}, \mathrm{Cl}^{-}, \mathrm{PO}_{4}{ }^{3-}, \mathrm{HCO}_{3}{ }^{-}$, and $\mathrm{SO}_{4}{ }^{2-}$ ) were tested against TNX in DMSO to determine their effects on the formation of the CT interaction with phosphate. The species were introduced to the TNX solution in both the presence and absence of phosphate. The absorbance of the resulting interaction was recorded, measuring the effect on the interaction that occurred. Of the species tested, none impeded the formation of the CT complex in the presence of phosphate and none initiated the interaction in the absence of phosphate. The species tested are the most common species found in urine, lending toward the application of the sensor. It can therefore be concluded that the sensor can operate in this complex medium without losing performance because of the presence of other species.

A dose-response curve was constructed across the physiological range of phosphate in urine, determining the intensity of the CT interaction stimulated. A range of $0.1-1.5$ $\mathrm{mg} \mathrm{mL} \mathrm{L}^{-1}$ was selected for the dose-response curve as this allowed phosphate levels outside the normal range to be studied. The dose-response curve demonstrated to be linear throughout the selected range, allowing easy verification of both hyper- and hypophosphatemia. CLSI guidelines were then followed in the determination of the LoB $(0.001 \mathrm{mg}$ $\left.\mathrm{mL}^{-1}\right)$, LoD $\left(0.164 \mathrm{mg} \mathrm{mL}^{-1}\right)$, and $\operatorname{LoQ}\left(\geq 0.164 \mathrm{mg} \mathrm{mL}^{-1}\right)$ of the sensor, using a standardized method of demonstrating the LoD of the sensor was lower than that of the lowest physiological relevant concentration.

The analysis of $24 \mathrm{~h}$ urine samples by means of CT interaction and a corresponding vanadate-molybdate reagent validation method yielded results within the physiological range. The results of both tests were within an acceptable tolerance for a PoC setting, with the TNX-based sensor giving a mildly weaker depiction of the phosphate concentration in the biological sample. The intrasample deviation was minor, demonstrating the reproducible and reliable nature of the proposed test. This added validity to that of the novel use of TNX in the formation of the CT complex in the presence of phosphate. Compared to vanadomolybdophosphoric acid colorimetry, the CT method was conducted without sample pretreatment, therefore reducing the analysis time, removing the use of toxic chemicals, and lending to a PoC diagnostic setting.

Overall, this study illustrates that TNX can be applied as a chemical phosphate sensor, demonstrating high reproducibility and sensitivity in analyzing phosphate levels in urine. The sensor demonstrates a strong selectivity toward phosphate, with other species not influencing the sensing capabilities. The rapid manner and ease of sample analysis demonstrated the versatile nature of the chemical sensor, with only microliters of sample necessary for a reading. Therefore, this method offers an alternative use for TNX in the field of anion sensing, where physiologically relevant levels of phosphate can be monitored. Thus, a facile method of phosphate detection is presented in a bid to easily recognize and diagnose potential CKD or hyperphosphatemia.

\section{MATERIALS AND METHODS}

4.1. Materials. All materials were used in their original form as received from commercial suppliers. Sodium chloride (99.5-100\%), sulfuric acid (37\%), nitric acid (90\%), calcium chloride (95\%), sodium bicarbonate (98\%), and sodium sulfate $(\geq 98 \%)$ were purchased from VWR Chemicals. Sodium phosphate (96\%), $m$-xylene (98\%), potassium phosphate tribasic (97\%), calcium phosphate ( $>96 \%)$, and magnesium phosphate $(98 \%)$ were supplied by Sigma-Aldrich. DMSO 
(99\%) used was purchased from Alfa Aesar. All the salts used contained a common sodium cation in order to eliminate any possible deviations induced by the use of different cationic species. A Shimadzu UV-3600 UV-vis-NIR spectrophotometer was used for the measurement and recording of UV spectra.

4.2. Synthesis of TNX. A stirred solution of water $(5 \mathrm{~mL})$, $\mathrm{H}_{2} \mathrm{SO}_{4}(5.5 \mathrm{~mL}, 37 \% \mathrm{w} / \mathrm{v})$, and $\mathrm{HNO}_{3}(5 \mathrm{~mL} 90 \% \mathrm{w} / \mathrm{v})$ was chilled to $5{ }^{\circ} \mathrm{C}$ before the dropwise addition of $m$-xylene $(5 \mathrm{~g}$, $0.047 \mathrm{~mol}$ ) over the course of $15 \mathrm{~min}$. Once completed, the reaction mixture was heated to $70{ }^{\circ} \mathrm{C}$ before the further dropwise addition of $\mathrm{HNO}_{3}(5 \mathrm{~mL})$, maintaining the temperature below $80{ }^{\circ} \mathrm{C}$. Next, the reaction temperature was slowly increased to $100{ }^{\circ} \mathrm{C}$ and then rapidly to $120{ }^{\circ} \mathrm{C}$ for $1 \mathrm{~h}$. The reaction mixture was then allowed to cool before being poured over ice and $100 \mathrm{~mL}$ of water being added. The impure TNX crystals then precipitated as a yellow powder that could be collected by vacuum filtration. Once collected, the crystals were recrystallized from acetone, yielding off-white needle-like crystals in high abundance. Yield: $89 \%,{ }^{1} \mathrm{H}$ NMR $\left(300 \mathrm{MHz}, \mathrm{DMSO}-d_{6}\right): \delta 8.85(\mathrm{~s}, 1 \mathrm{H}), 2.47(\mathrm{~s}, 6 \mathrm{H}) .{ }^{13} \mathrm{C} \mathrm{NMR}$ $\left(75 \mathrm{MHz}, \mathrm{DMSO}-d_{6}\right): \delta 153.56,147.82,130,23,122.98,15.01$. mp $184{ }^{\circ} \mathrm{C}$. LCMS $[\mathrm{M}+1] \mathrm{m} / \mathrm{z}^{*}: 242.159$.

4.3. Analysis of $C T$ Interaction Formation and Stability ( ${ }^{1} \mathrm{H}$ NMR/UV/FTIR Spectroscopy). A $5 \mathrm{mg} \mathrm{mL}^{-1}$ solution of TNX in DMSO- $d_{6}$ was prepared and initially analyzed with ${ }^{1} \mathrm{H}$ NMR (300 MHz) and FTIR spectroscopies to gain free electron acceptor spectra for the experiment. The TNX DMSO $(6 \mathrm{~mL})$ solution was then subjected to $50 \mu \mathrm{L}$ potassium phosphate $\left(5 \mathrm{mg} \mathrm{mL} \mathrm{m}^{-1}\right)$, prepared in DMSO- $d_{6}$, initiating the CT interaction. ${ }^{1} \mathrm{H} \mathrm{NMR}, \mathrm{UV}\left(\lambda_{\max }=664 \mathrm{~nm}\right)$, and FTIR spectra were collected directly after the initial addition of the phosphate anions and then again every hour for a $6 \mathrm{~h}$ period, allowing the electronic interactions and stability of the complex to be studied. A Shimadzu UV-3600 spectrophotometer was used for the collection of the UV data with a standard $3.5 \mathrm{~mL}$ quartz cuvette and a path length of $1 \mathrm{~cm}$.

4.4. Job's Plot: Stoichiometric Study. Two solutions were prepared: (a) containing TNX $(4.15 \mathrm{mM})$ in DMSO/ $\mathrm{H}_{2} \mathrm{O}(9: 1 \mathrm{v} / \mathrm{v})$ and (b) containing potassium phosphate (tribasic) $(2.35 \mathrm{mM})$ in $\mathrm{DMSO} / \mathrm{H}_{2} \mathrm{O}(9: 1 \mathrm{v} / \mathrm{v})$. The sum of the molar concentrations of these two binding partners was kept constant, whereas the molar fractions of each introduced to one another were varied. To this end, the TNX solution was introduced to the phosphate solution (1:9), the components were mixed well, and the UV absorbance spectra of the resulting solution were collected $(250-800 \mathrm{~nm})$. This was repeated for the other molar fractions $(2: 8,3: 7,4: 6,5: 5,6: 4$, $7: 3,8: 2,9: 1)$, with each molar fraction analyzed by the same method. A Shimadzu UV-3600 spectrophotometer $(3.5 \mathrm{~mL}$ quartz cuvette, path length of $1 \mathrm{~cm}$ ) was used for data collection, and the maximum absorbance peak $\left(\lambda_{\max }=664 \mathrm{~nm}\right)$ of each sample was compared. All samples were repeated in triplet, with the average values and SDs reported.

4.5. Effects of Water on Complex Degradation. $\mathrm{K}_{3} \mathrm{PO}_{4}$ was dissolved in DMSO $\left(5 \mathrm{mg} \mathrm{mL}^{-1}\right)$, and a $50 \mu \mathrm{L}$ aliquot was added to a $6 \mathrm{~mL}$ solution of TNX in DMSO $\left(5 \mathrm{mg} \mathrm{mL}^{-1}\right)$. The two reactants were shaken vigorously for $1 \mathrm{~min}$ before collecting the UV spectra of the sample. The absorbance $\left(\lambda_{\max }=664 \mathrm{~nm}\right)$ of this solution was then recorded before the addition of $50 \mu \mathrm{L}$ of DI water, shaking the solution vigorously once more. This process was repeated for each volume of DI water stated (see below), and a total volume of $4.5 \mathrm{~mL}$ of DI water had successfully been added to the system. A Shimadzu UV-3600 spectrophotometer ( $3.5 \mathrm{~mL}$ quartz cuvette, path length of $1 \mathrm{~cm}$ ) was used to record the UV spectra of each sample. The experiment was then repeated in triplet, allowing the mean values and standard deviations to be calculated. The total volume of DI water in the mixture was gradually increased stepwise as follows: 200, 400, 600, 800, 1000, 1500, 2000, 2500, 3000, 3500, 4000, and $4500 \mu \mathrm{L}$.

4.6. Solvent Effects on CT Complexation. $\mathrm{K}_{3} \mathrm{PO}_{4}(5 \mathrm{mg}$ $\left.\mathrm{mL}^{-1}, 50 \mu \mathrm{L}\right)$ was added to a TNX solution in a defined solvent $\left(5 \mathrm{mg} \mathrm{mL} \mathrm{m}^{-1}, 5 \mathrm{~mL}\right)$. To ensure homogeneity of the solution, it was shaken thoroughly before noting the observed color change and collecting the UV spectra using a Shimadzu UV-3600 spectrophotometer (3.5 mL quartz cuvette, path length of $1 \mathrm{~cm}$ ) after $1 \mathrm{~min}$ of initiating the reaction. The solvent effect on the CT mechanism was examined by changing the solvent used in the experiment (acetone, DMF, and DMSO).

4.7. Optimization of TNX Concentration and Sample Volume. Stock solutions of TNX in DMSO $\left(2.5 \mathrm{mg} \mathrm{mL}^{-1}\right)$ and $\mathrm{K}_{3} \mathrm{PO}_{4}\left(1.125 \mathrm{mg} \mathrm{mL}^{-1}\right)$ in DI water were prepared. To a $6 \mathrm{~mL}$ aliquot of the TNX solution was added $50 \mu \mathrm{L}$ of $\mathrm{K}_{3} \mathrm{PO}_{4(\mathrm{aq})}$, and the absorbance spectra were recorded with a Shimadzu UV-3600 spectrophotometer $(3.5 \mathrm{~mL}$ quartz cuvette, path length of $1 \mathrm{~cm}$ ) after $1 \mathrm{~min}$ of initiating the reaction. This was repeated, increasing the total volume of phosphate added to the TNX solution with each addition (overall volume of phosphate: 50,100, 200, 400, and $500 \mu \mathrm{L}$ ), thus allowing the effect of the volume of phosphate on the CT band intensity $\left(\lambda_{\max }=664 \mathrm{~nm}\right)$ to be studied. This experiment was repeated for various concentrations of TNX solution (2.5, $1.0,0.5$, and $\left.0.1 \mathrm{mg} \mathrm{mL}^{-1}\right)$ and phosphate $(0.350$, and 1.125 $\mathrm{mg} \mathrm{mL}^{-1}$ ), being representative of the physiologically relevant extremes.

4.8. Effect of Interferences on the Formation of the CT Interaction. A stock solution $\left(1 \mathrm{mg} \mathrm{mL}^{-1}\right)$ was prepared by dissolving TNX in DMSO, shaking the solution thoroughly, ensuring that all crystals of TNX were fully dispersed. Isolated ionic interferences $\left(\mathrm{CH}_{3} \mathrm{CH}_{2} \mathrm{OH}, \mathrm{Na}^{+}, \mathrm{K}^{+}, \mathrm{Ca}^{2+}, \mathrm{Cl}^{-}, \mathrm{PO}_{4}{ }^{3-}\right.$, $\mathrm{F}^{-}, \mathrm{CH}_{3} \mathrm{COO}^{-}, \mathrm{HCO}_{3}{ }^{-}$, and $\mathrm{SO}_{4}{ }^{2-}$ ) were prepared in both $\mathrm{DI}$ water and $\mathrm{K}_{3} \mathrm{PO}_{4(\mathrm{aq})}\left(0.85 \mathrm{mg} \mathrm{mL} \mathrm{m}^{-1}\right)$ according to the physiological concentrations found in urine (see Supporting Information S9). ${ }^{48}$ To $6 \mathrm{~mL}$ aliquots of the TNX solution was added $400 \mu \mathrm{L}$ of the potential interfering species, in either DI water or phosphate solution, respectively. Each species was introduced to the TNX solution separately, enabling to study the individual effect on the CT interaction for each of the anionic species. The spectra for each species were collected with a Shimadzu UV-3600 spectrophotometer $(3.5 \mathrm{~mL}$ quartz cuvette, path length of $1 \mathrm{~cm})$, with the most intense peak $\left(\lambda_{\max }\right.$ $=664 \mathrm{~nm}$ ) being monitored. Each sample was repeated in triplet, with the mean readings being plotted with the corresponding SDs.

4.9. Optimized Dose-Response for Phosphate Detection. A dose-response study was done by reacting 6 $\mathrm{mL}$ aliquots of TNX in DMSO $\left(1 \mathrm{mg} \mathrm{mL}^{-1}\right)$ and adding 400 $\mu \mathrm{L}$ of aqueous $\mathrm{K}_{3} \mathrm{PO}_{4}$ in the concentration range of $0.1-1.5$ $\mathrm{mg} \mathrm{mL} \mathrm{m}^{-1}$. Each sample was analyzed with a Shimadzu UV3600 spectrophotometer $(3.5 \mathrm{~mL}$ quartz cuvette, path length of $1 \mathrm{~cm}$ ) within $1 \mathrm{~min}$ of initiating the reaction, and the absorbance of the most intense peak $\left(\lambda_{\max }=664 \mathrm{~nm}\right)$ was plotted against the corresponding concentration of phosphate 
to obtain a dose-response curve. Each concentration was analyzed in triplet, with mean readings and SDs plotted.

4.10. Validation Method (Vanadomolybdophosphoric Acid Colorimetric Method). Ammonium molybdate (2.5 g, $12.75 \mathrm{mmol}$ ) was dissolved in $30 \mathrm{~mL}$ of DI water, generating solution A. To generate solution $\mathrm{B}$, ammonium metavanadate $(0.13 \mathrm{~g}, 1.1 \mathrm{mmol})$ was dissolved in $30 \mathrm{~mL}$ of DI water and 33 $\mathrm{mL}$ of concentrated hydrochloric acid (37\%), before allowing the solution to cool to room temperature. Solutions A and B were then added to each other before diluting the overall volume to $100 \mathrm{~mL}$ with DI water. A dilution series of aqueous $\mathrm{K}_{3} \mathrm{PO}_{4}\left(0.1-1.5 \mathrm{mg} \mathrm{mL}{ }^{-1}, 1 \mathrm{~mL}\right)$ was then introduced to 3 $\mathrm{mL}$ of the vanadate-molybdate reagent and $5 \mathrm{~mL}$ of DI water, with $20 \mu \mathrm{L}$ of the resulting solution diluted to an overall volume of $5 \mathrm{~mL}$ with DI water, thus enabling the construction of a dose-response curve. Each concentration was analyzed with a Shimadzu UV-3600 spectrophotometer $(3.5 \mathrm{~mL}$ quartz cuvette, path length of $1 \mathrm{~cm}$ ), determining the absorbance at $\lambda_{\max }=308 \mathrm{~nm}$. The urine samples previously tested with the TNX-based phosphate sensor were then analyzed with the vanadate-molybdate reagent in the same manner, and the phosphate concentrations were verified. Each sample was analyzed in triplet as perprevious methods.

4.11. Phosphate Analysis of Urine. The concentration of phosphate in urine samples was analyzed using the parameters optimized in the previously described experiments. To this end, $400 \mu \mathrm{L}$ of urine was pipetted into a $6 \mathrm{~mL}$ aliquot of TNX in DMSO $\left(1 \mathrm{mg} \mathrm{mL} \mathrm{m}^{-1}\right)$, and the solution was shaken thoroughly for $1 \mathrm{~min}$. The sample was transferred into a quartz cuvette, collecting the UV spectrum and noting the maximum absorbance band $\left(\lambda_{\max }=664 \mathrm{~nm}\right)$. This absorbance was then correlated with the previously generated doseresponse graph, giving an indication of the phosphate levels present in the sample. The analysis was repeated with the validation method outlined above; however, the color of the urine was removed by filtration with activated charcoal prior to analysis. The urine supplied was collected from a healthy consenting volunteer (author of the paper) over a $24 \mathrm{~h}$ period, giving a representative sample of daily phosphate concentrations.

\section{ASSOCIATED CONTENT}

\section{(s) Supporting Information}

The Supporting Information is available free of charge at https://pubs.acs.org/doi/10.1021/acsomega.0c02651.

Detailed analysis of FTIR data; Job's plot of the TNX complex; enhanced ${ }^{1} \mathrm{H}$ NMR image; colorimetric titration of TNX with phosphate; second-order degradation graph of the CT complex; $R^{2}$ values of optimized parameters; raw validation data with the dose response; raw data of phosphate in urine analyzed by both the TNX sensor and the validation method; and common physiological interferences in urine (PDF)

\section{AUTHOR INFORMATION}

\section{Corresponding Author}

Joseph W. Lowdon - Sensor Engineering Department, Faculty of Science and Engineering, Maastricht University, Maastricht 6200 MD, The Netherlands; Email: joe.lowdon@ maastrichtuniversity.nl

\section{Authors}

Hikaru Ishikura - Maastricht Science Programme, Faculty of Science and Engineering, Maastricht University, Maastricht 6200 MD, The Netherlands

Ash Radchenko - Maastricht Science Programme, Faculty of Science and Engineering, Maastricht University, Maastricht 6200 MD, The Netherlands

Rocio Arreguin-Campos - Sensor Engineering Department, Faculty of Science and Engineering, Maastricht University, Maastricht 6200 MD, The Netherlands

Renato Rogosic - Sensor Engineering Department, Faculty of Science and Engineering, Maastricht University, Maastricht 6200 MD, The Netherlands; (1) orcid.org/0000-0002-1331$600 \mathrm{X}$

Benjamin Heidt - Sensor Engineering Department, Faculty of Science and Engineering, Maastricht University, Maastricht 6200 MD, The Netherlands

Kathia Jimenez Monroy - Sensor Engineering Department, Faculty of Science and Engineering, Maastricht University, Maastricht 6200 MD, The Netherlands

Marloes Peeters - School of Engineering, Newcastle University, Tyne NE1 7RU, U.K.; 이이.org/0000-0002-0429-8073

Hanne Diliën - Sensor Engineering Department, Faculty of Science and Engineering, Maastricht University, Maastricht 6200 MD, The Netherlands

Kasper Eersels - Sensor Engineering Department, Faculty of Science and Engineering, Maastricht University, Maastricht 6200 MD, The Netherlands; ㅇo orcid.org/0000-0002-02141320

Thomas J. Cleij - Sensor Engineering Department, Faculty of Science and Engineering, Maastricht University, Maastricht 6200 MD, The Netherlands; ㅇorcid.org/0000-0003-01729330

Bart van Grinsven - Sensor Engineering Department, Faculty of Science and Engineering, Maastricht University, Maastricht 6200 MD, The Netherlands; 이이. orcid.org/000-0002-69390866

Complete contact information is available at:

https://pubs.acs.org/10.1021/acsomega.0c02651

\section{Author Contributions}

A.R. and J.W.L. developed the anionic sensing idea, conducting preliminary measurements, dose-responses, and degradation studies. H.I. conducted selectivity measurements and compiled the data for these experiments. R.R. and B.H. helped with data collection, processing, and fitting. J.W.L. and R.A.-C. performed NMR, FTIR, and UV analyses of samples in collaboration with H.D. and T.J.C. Insights and feedback in designing experiments and examining the potential medical and biological impacts were provided by B.v.G., M.P., K.J.M., and K.E. The manuscript was jointly written by J.W.L. and K.E.

Notes

The authors declare no competing financial interest.

\section{ACKNOWLEDGMENTS}

The authors are grateful to the province of Limburg, The Netherlands, for funding through the "Limburg Meet" project . Technical support by numerous Maastricht Science Programme undergrad students is greatly appreciated, with a special mention to Yuy Buchwaldt for assistance with analytical equipment and analysis. 


\section{REFERENCES}

(1) Gunnlaugsson, T.; Glynn, M.; Tocci, G. M.; Kruger, P. E.; Pfeffer, F. M. Anion recognition and sensing in organic and aqueous media using luminescent and colorimetric sensors. Coord. Chem. Rev. 2006, 250, 3094-3117.

(2) Gale, P. A.; García-Garrido, S. E.; Garric, J. Anion receptors based on organic frameworks: highlights 2006. Chem. Soc. Rev. 2008, 37, 151-190.

(3) Prados, P.; Quesada, R. Recent advances in macrocyclic and macrocyclic-based anion receptors. Supramol. Chem. 2008, 20, 201.

(4) Katayev, E. A.; Ustynyuk, Y. A.; Sessler, J. L. Receptors for tetrahedral oxyanions. Coord. Chem. Rev. 2006, 250, 3004.

(5) Jackson, R. K.; Shi, Y.; Yao, X.; Burdette, S. C. FerriNaphth: A fluorescent chemodosimeter for redox active metal ions. Dalton Trans. 2010, 39, 4155 .

(6) de Silva, A. P.; Rice, T. E. A small supramolecular system which emulates the unidirectional, path-selective photoinduced electron transfer (PET) of the bacterial photosynthetic reaction centre (PRC). Chem. Commun. 1999, 163-164.

(7) Hruska, K. A.; Teitelbaum, S. L. Renal osteodystrophy. N. Engl. J. Med. 1995, 333, 166-175.

(8) Slatopolsky, E.; Weerts, C.; Lopez-Hilker, S.; Norwood, K.; Zink, M.; Windus, D.; Delmez, J. Calcium carbonate as a phosphate binder in patients with chronic renal failure undergoing dialysis. N. Engl. J. Med. 1986, 315, 157-161.

(9) Slatopolsky, E. A.; Burke, S. K.; Dillon, M. A. RenaGel, a nonabsorbed calcium and aluminum-free phosphate-binder, lowers serum phosphorus and parathyroid hormone. Kidney Int. 1999, 55, 299-307.

(10) Canfarotta, F.; Czulak, J.; Betlem, K.; Sachdeva, A.; Eersels, K.; Van Grinsven, B.; Cleij, T. J.; Peeters, M. A novel thermal detection method based on molecularly imprinted nanoparticles as recognition elements. Nanoscale 2018, 10, 2081-2089.

(11) Diliën, H.; Peeters, M.; Royakkers, J.; Harings, J.; Cornelis, P.; Wagner, P.; Steen Redeker, E.; Banks, C. E.; Eersels, K.; van Grinsven, B.; Cleij, T. J. Label-Free Detection of Small Organic Molecules by Molecularly Imprinted Polymer Functionalized Thermocouples: Toward In Vivo Applications. ACS Sens. 2017, 2, 583-589.

(12) Lowdon, J. W.; Eersels, K.; Rogosic, R.; Heidt, B.; Diliën, H.; Redeker, E. S.; Peeters, M.; van Grinsven, B.; Cleij, T. J. Substrate displacement colorimetry for the detection of diarylethylamines. Sens. Actuators, B 2019, 282, 137-144.

(13) Wiskur, S. L.; Ait-Haddou, H.; Lavigne, J. J.; Anslyn, E. V. Teaching old indicators new tricks. Acc. Chem. Res. 2001, 34, 963972.

(14) Sessler, J. L.; Gale, P. A.; Cho, W. S. Anion Receptor Chemistry; Stoddart, J. F., Ed.; Monographs in Supramolecular Chemistry; Royal Society of Chemistry: Cambridge, 2006; pp 259-293.

(15) Duke, R. M.; Veale, E. B.; Pfeffer, F. M.; Kruger, P. E.; Gunnlaugsson, T. Colorimetric and fluorescent anion sensors: an overview of recent developments in the use of 1,8-naphthalimidebased chemosensors. Chem. Soc. Rev. 2010, 39, 3936-3953.

(16) Bhosale, S. V.; Bhosale, S. V.; Kalyankar, M. B.; Langford, S. J. A core-substituted naphthalene diimide fluoride sensor. Org. Lett. 2009, 11, 5418-5421.

(17) Singh, A.; Sahoo, S. K.; Trivedi, D. R. Colorimetric anion sensors based on positional effect of nitro groups for recognition of biologically relevant anions in organic and aqueous medium, insight real-life application and DFT studies. Spectrochim. Acta, Part A 2018, $188,596-610$.

(18) Okudan, A.; Erdemir, S.; Kocyigit, O. 'Naked-eye' detection of fluoride and acetate anions by using simple and efficient urea and thiourea based colorimetric sensors. J. Mol. Struct. 2013, 1048, 392398.

(19) Duke, R. M.; O’Brien, J. E.; McCabe, T.; Gunnlaugsson, T. Colorimetric sensing of anions in aqueous solution using charge neutral, cleft-like, amideothioeurea receptor: tilting the balance between hydrogen bonding and deprotonation in anion recognition. Org. Biomol. Chem. 2008, 6, 4089-4092.
(20) Kumari, N.; Jha, S.; Bhattacharya, S. Colorimetric probes based on anthraimidazolediones for selective sensing of fluoride and cyanide ion via intramolecular charge transfer. J. Org. Chem. 2011, 76, 82158222.

(21) Beer, P. D.; Gale, P. A. Anion Recognition and Sensing: The State of the Art and Future Perspectives. Angew. Chem., Int. Ed. 2001, $40,486-516$

(22) Gunnlaugsson, T.; Kruger, P. E.; Lee, T. C.; Parkesh, R.; Pfeffer, F. M.; Hussey, G. M. Simple naphthalimide based anion sensors: deprotonation induced colour changes and $\mathrm{CO} 2$ fixation. Tetrahedron Lett. 2003, 44, 8909-8913.

(23) Birks, J. B.; Christophorou, L. G. Excimer Formation in Polycyclic Hydrocarbons and their Derivatives. Nature 1963, 197, 1064-1065.

(24) Murphy, J.; Riley, J. P. A single-solution method for the determination of soluble phosphate in sea water. J. Mar. Biol. Assoc. U. K. 1958, 37, 9-14.

(25) Dickman, S. R.; Bray, R. H. Colorimetric determination of phosphate. Ind. Eng. Chem. 1940, 12, 665-668.

(26) Robards, K.; McKelvie, I. D.; Benson, R. L.; Worsfold, P. J.; Blundell, N. J.; Casey, H. Determination of carbon, phosphorus, nitrogen and silicon species in waters. Anal. Chim. Acta 1994, 287, 147-190.

(27) Mainstone, C. P.; Parr, W. Phosphorus in rivers - ecology and management. Sci. Total Environ. 2002, 282-283, 25-47.

(28) Metzger, A.; Anslyn, E. V. A chemosensor for citrate in beverages. Angew. Chem., Int. Ed. 1998, 37, 649-652.

(29) Marshall, J. The Manufacture of Trinitroxylene for Use as a Substitute for TNT in Bursting Charges for High Explosive Shell. J. Ind. Eng. Chem. 1920, 12, 248-250.

(30) Arienzo, M. Degradation of 2,4,6-trinitrotoluene in water and soil slurry utilizing a calcium peroxide compound. Chemosphere 2000, 40, 331-337.

(31) Patil, P. D. J.; Ingle, R. D.; Wagelgave, S. M.; Bhosale, R. S.; Bhosale, S. V.; Pawar, R. P.; Bhosale, S. V. A naphthalimidebenzothiazole conjugate as colorimetric and fluorescent sensor for selective trinitrophenol detection. Chemosensors 2019, 7, 38.

(32) Zhang, X.; Chen, S.; Jin, S.; Zhang, Y.; Chen, X.; Zhang, Z.; Shu, Q. Naphthalene based lab-on-a-molecule for fluorometric and colorimetric sensing of F- and CN- and nitroaromatic explosives. Sens. Actuators, B 2017, 242, 994-998.

(33) Sherif, Z. A. E. Spectrophotometric Determination of Enrofloxacin Through the Formation of a Binary Complex with Iron III, Ion-Pair and Charge-Transfer Complexation in Pure and Dosage Forms. Anal. Lett. 1999, 32, 65-78.

(34) Amendola, V.; Esteban-Gómez, D.; Fabbrizzi, L.; Licchelli, M. What anions do to N-H-containing receptors. Acc. Chem. Res. 2006, 39, 343-353.

(35) Reena, V.; Suganya, S.; Velmathi, S. Synthesis and anion binding studies of azo-schiff bases; selective colorimetric fluoride and acetate ion sensors. J. Fluorine Chem. 2013, 153, 89-95.

(36) Karmakar, A.; Singh, B. Spectroscopic and theoretical studies of charge-transfer interaction of 1-(2-pyridylazo)-2-napthol with nitroaromatics. Spectrochim. Acta, Part A 2017, 179, 110-119.

(37) Dong, W.; Pina, J.; Pan, Y.; Preis, E.; de Melo, J. S. S.; Scherf, $\mathrm{U}$. Polycerbazoles and polytriphenylamines showing aggregationinduced emission (AIE) and intramolecular charge transfer (ICT) behavior for the optical detection of nitroaromatic compounds. Polymer 2015, 76, 173-181.

(38) Reddy, M. N.; Swapna, M.; Rao, K. V. K.; Sankar, D. G.; Sridhar, K. Spectrophotometric determination of ciprofloxacin, enrofloxacin and pefloxacin through charge transfer complex formation. Indian Drugs 1998, 35, 105-106.

(39) Venkatappa, L.; Ture, S. A.; Yelamaggad, C. V.; Sundaram, V. N. N.; Martínez-Máñez, R.; Abbaraju, V. Mechanistic insight into the turn-off sensing of nitroaromatic compounds employing functionalized polyaniline. ChemistrySelect 2020, 5, 6321-6330.

(40) Sakki, B.; Maghchiche, A.; Nasri, R.; Bouras, O.; Haouam, A. Synthesis and characterization of the charge transfer complexes 
polyvinyl carbazole with trinitrofluorenone. J. Fund. Appl. Sci. 2020, 12, 389-398.

(41) Colin, J. J.; de Claubry, H. G. On the reactions of iodine with vegetable and animal materials. Ann. Chim. 1814, 90, 87.

(42) Jin, J.; Wu, S.; Ma, Y.; Dong, C.; Wang, W.; Liu, X.; Xu, H.; Long, G.; Zhang, M.; Zhang, J.; Huang, W. Nucleation controltriggering cocrystal polymorphism of charge transfer complexes differing in physical and electronic properties. ACS Appl. Mater. Interfaces 2020, 12, 19718-19726.

(43) Abdel-Kader, M. H.; Issa, R. M.; Ayad, M. M.; Abdel-Mottaleb, M. S. Charge transfer complexes of aromatic nitrocompounds with disubstituted naphthalenes. I. Spectroscopic Investigation of the Donor Behaviour of the 2, 6-and 23-Dimethylnaphthalene. $Z$. Naturforsch., A: Phys. Sci. 1984, 39, 1274-1278.

(44) El-Didamony, A. M.; Ramadan, G. M. Charge-transfer interaction between antihistamine antiallergic drugs, diphenhydramine, fexofenadine, cetirizine and two $\pi$-acceptors in pharmaceutical forms. SN Appl. Sci. 2020, 2, 723.

(45) Forte-Tavčer, P. Interactions between some anionic dyes and cationic surfactants with different alkyl chain length studied by the method of continuous variations. Dyes Pigm. 2004, 63, 181-189.

(46) Kuro-o, M. A phosphate-centric paradigm for pathophysiology and therapy of chronic kidney disease. Kidney Int. Suppl. 2013, 3, $420-426$.

(47) Armbruster, D. A.; Pry, T. Limit of Blank, Limit of Detection and Limit of Quantification. Clin. Biochem. Rev. 2008, 29, S49-S52.

(48) Kirchmann, H.; Pettersson, S. Human urine - chemical composition and fertilizer use efficiency. Fert. Res. 1995, 40, 149-154. 